\title{
Heritability and Environmental Correlation of Phase Angle with Anthropometric Measurements: A Twin Study
}

\author{
Daisuke Matsumoto ${ }^{1,2,3, *(D)}$, Fujio Inui ${ }^{2,3,4}$, Chika Honda ${ }^{3,5}$, Rie Tomizawa ${ }^{3}$, \\ Mikio Watanabe ${ }^{3,6} \oplus^{\circ}$, Karri Silventoinen ${ }^{3,7}$ and Norio Sakai ${ }^{3,8}$ \\ 1 Department of Physical Therapy, Faculty of Health Sciences, Kio University, 4-2-2 Umaminaka, Koryo-cho, \\ Kitakatsuragi-gun, Nara 635-0832, Japan \\ 2 Health Promotion Center, Kio University, 4-2-2 Umaminaka, Koryo-cho, Kitakatsuragi-gun, Nara 635-0832, \\ Japan; f.inui@kio.ac.jp \\ 3 Center for Twin Research, Osaka University Graduate School of Medicine, Suita, Osaka 565-0871, Japan; \\ honda-ch@sahs.med.osaka-u.ac.jp (C.H.); r-tomizawa@sahs.med.osaka-u.ac.jp (R.T.); \\ nabe@sahs.med.osaka-u.ac.jp (M.W.); karri.silventoinen@helsinki.fi (K.S.); \\ norio@sahs.med.osaka-u.ac.jp (N.S.) \\ 4 Department of Nursing, Faculty of Health Sciences, Kio University, 4-2-2 Umaminaka, Koryo-cho, \\ Kitakatsuragi-gun, Nara 635-0832, Japan \\ 5 Faculty of Nursing, Shiga University of Medical Science, Seta Tsukinowa-cho, Otsu, Shiga 520-2192, Japan \\ 6 Department of Clinical Laboratory and Biomedical Sciences, Division of Health Sciences, \\ Osaka University Graduate School of Medicine, Suita, Osaka 565-0871, Japan \\ 7 Department of Social Research, Faculty of Social Sciences, University of Helsinki, P.O. Box 18, \\ 00014 Helsinki, Finland \\ 8 Child Healthcare and Genetic Science Laboratory, Division of Health Sciences, \\ Osaka University Graduate School of Medicine, Suita, Osaka 565-0871, Japan \\ * Correspondence: d.matsumoto@kio.ac.jp; Tel.: +81-745-54-1601
}

Received: 9 October 2020; Accepted: 22 October 2020; Published: 26 October 2020

\begin{abstract}
Bioelectrical impedance analysis (BIA)-derived phase angle ( $\mathrm{PhA})$ is a valuable parameter to assess physical health. However, the genetic and environmental aspects of PhA are not yet well understood. The present study aimed to estimate the heritability of $\mathrm{PhA}$ and investigate the relationships between PhA and anthropometric measurements. PhA and skeletal muscle mass index (SMI) were examined using multi-frequency BIA in 168 Japanese twin volunteers (54 males and 114 females; mean age $=61.0 \pm 16.5$ years). We estimated the narrow-sense heritability of these parameters and the genetic and environmental relationships between them using a genetic twin modeling. For the PhA, 51\% (95\% confidence interval: $0.33,0.64)$ of the variance was explained by additive genetic effects, and $49 \%$ (95\% confidence interval: $0.36,0.67)$ was explained by unique environmental effects. The heritability of PhA was lower than the height, body weight, and body mass index. PhA shared almost no genetic variation with anthropometric measurements and SMI but shared an environmental variation (14\%) with SMI. These findings suggest that the genes affecting $\mathrm{PhA}$ are different than those affecting anthropometric measurements and SMI. The correlation between PhA and SMI is caused by common environmental factors.
\end{abstract}

Keywords: phase angle; heritability; twin study; anthropometric measurements

\section{Introduction}

Bioelectrical impedance analysis (BIA) has been widely used as a non-invasive, inexpensive, and quick technique to estimate body composition by sending a weak electric current $[1,2]$. BIA works 
mainly through the measuring of body resistance and reactance to alternate electrical current. Resistance depends on the fluid and electrolyte content of the body. Cell membranes produce reactance by storing parts of the charge as a capacitor. This storage of the current creates a phase shift that can be seen as the ratio of resistance and reactance and is presented geometrically as the phase angle ( $\mathrm{PhA})$ [3]. $\mathrm{PhA}$ is one of the parameters of BIA that is related to cell size or integrity (structure) of the cell membrane [3], and it may be a suitable marker for nutritional assessment [4,5]. A systematic review [6] found that 42 of 48 selected studies showed a correlation between low PhA and mortality. Thus, PhA seems to be a good predictor of mortality in many clinical situations, especially kidney disease and cancer, and can be used for screening individuals prone to these diseases. Recently, researchers have proposed that PhA is a good indicator of sarcopenia [7], falling [8], frailty [9], incident disability [10], and quality of life [11].

In addition, age-related changes in PhA have been reported previously in the context of whole-body measures of body composition [12]. PhA is related to muscle mass and strength in elderly subjects [13], and 12 weeks of resistance training in untrained older women can improve PhA. Furthermore, changes in muscle quality are positively correlated with changes in PhA [14]. According to the European Working Group on Sarcopenia in Older People (EWGSOP2), muscle quality can be assessed by a BIA-derived PhA measurement [15]. In the future, assessments of muscle quality are expected to guide treatment choices and monitor response to treatment [16].

Anthropometric measurements such as height, body weight, body mass index (BMI), and muscle mass phenotypes are influenced by genetic factors [17-19]. The heritability of BMI (0.51-0.77) is found to be largely similar in different populations and time periods despite large differences in mean BMI and variances of BMI [19]. Moreover, body fat mass and free-fat mass were also high but less heritable than height, body weight, and BMI [20,21]. Despite the previously mentioned prognostic potentials of $\mathrm{PhA}$, there are no studies assessing the heritability of PhA. We hypothesized that the heritability of PhA would be lower than height, body weight, BMI, and muscle mass and have less genetic influence. Therefore, using structural equation modelling (SEM), the present study aimed to estimate the heritability of $\mathrm{PhA}$. In addition, we examined whether PhA share the same genetic or environmental variation with anthropometric measurements by Cholesky decomposition.

\section{Materials and Methods}

\subsection{Participants}

The twin volunteers were recruited from the registry established by the Center for Twin Research, Osaka University, between June 2018 and December 2019. Eligibility criteria of the present study were the following: (1) Aged 20 years or older, (2) same-sex twin pairs, and (3) no dementia. We examined a total of 168 participants (54 males and 114 females): 75 monozygotic (MZ) twin pairs $(n=150)$ and nine same-sex dizygotic (DZ) twin pairs $(n=18)$.

The study protocol was approved by the ethics committee of the Osaka University (696-5 and 10209-15). All study participants provided informed consent, and participant anonymity was preserved. The study was conducted according to the provisions of the Declaration of Helsinki.

\subsection{Measurements}

Height was measured with a stadiometer to the nearest $0.1 \mathrm{~cm}$ while standing without shoes. A body composition analyzer (MC-780A; TANITA Co., Ltd., Tokyo, Japan) was used to determine body weight and bioelectrical impedance. Participants were instructed to stand bare feet on the metal footplate of the analyzer, holding the metallic grip electrodes with arms straight and pointed downwards in a neutral standing position. We performed the examination in the morning after $12 \mathrm{~h}$ of fasting and sufficient rest to optimize the results of the BIA analysis. In addition, the skeletal muscle mass index (SMI) was determined as the appendicular skeletal muscle mass (kg) divided by height 
squared $[16,22]$. Resistance $(\mathrm{R})$ and reactance $\left(\mathrm{XC}_{\mathrm{C}}\right)$ measured at $50 \mathrm{kHz}$ were used for calculation of the $\mathrm{PhA}$ with the following equation [8]:

$$
\operatorname{PhA}(\text { degrees })=-\operatorname{arc} \text { tangent }\left(\mathrm{Xc}_{\mathrm{C}} \mathrm{R}\right) \times(180 / \pi) .
$$

\subsection{Statistical Analysis}

To evaluate the relative importance of genetic and environmental factors for the measured phenotype, we used SEM. Individual differences in a trait can be decomposed into genetic and environmental sources of variance [23]. The sources of genetic and environmental variation considered in behavioral genetics are as follows: Additive genetic factors (A); dominance genetic factors (D); environmental factors shared by both twins (family member) $(C)$; and environmental factors unique to each twin individual and also measurement error (E). SEM represents a unified platform for path analysis and variance components of models and is the current method that is used to analyze twin data [24]. The heritability, which is calculated by SEM, was called the narrow-sense heritability. Because (C) and (D) components cannot be estimated simultaneously in the classical twin model with twins reared together, either the ACE or ADE model is fitted [25]. In this study, we illustrate the ACE model as an example. In the model, the following possible parameter combinations are considered: $\mathrm{ACE}, \mathrm{AE}$, $\mathrm{CE}$, and $\mathrm{E}$.

A full model (ACE model), including all latent variables, was examined against nested sub-models (AE, $\mathrm{CE}$, and $\mathrm{E}$ ) with the reduced numbers of parameters to find the most parsimonious model. The fittings of the alternative models were compared with the difference in $-2 \log$ likelihood, which.is asymptotically distributed as $x^{2}$ with degrees of freedom equal to the difference in the number of parameters. The fittings of the different models were also analyzed according to Akaike's information criterion [26], in which a smaller value indicates a better model. The estimates with $95 \%$ confidence intervals (CI) were obtained from the theoretically most acceptable and most parsimonious model, respectively. A path diagram of the univariate ACE model is shown in Figure 1, and the model represents the equation, which follows.

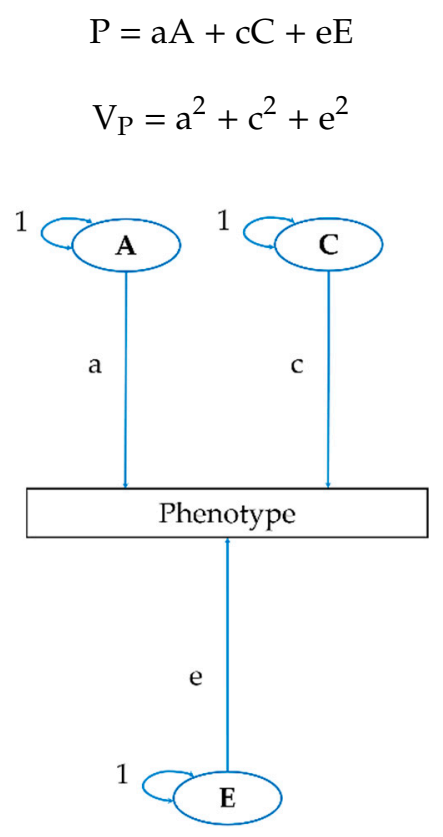

Figure 1. Path diagram for the univariate ACE model. (A) Additive genetic factor; (a) the path from a genetic factor; $(C)$ shared environmental factor; (c) the path from a shared environmental factor; (E) non-shared environmental factor; (e) the path from a non-shared environmental factor. 
The variables represent the following: $\mathrm{P}=$ phenotype; $\mathrm{V}_{\mathrm{P}}=$ total variance of the phenotype; $\mathrm{a}=$ the path from a genetic factor; $c=$ the path from a shared environmental factor; and $\mathrm{e}=$ the path from $\mathrm{a}$ non-shared environmental factor.

Furthermore, we used Cholesky decomposition to evaluate the relationship between phenotypes [27]. In the Cholesky decomposition, the first factor influences all the variables, the second factor influences all of them except for the first one, and so on. A path diagram of the bivariate Cholesky decomposition model is shown in Figure 2. The model represents the equation, which follows.

$$
\begin{gathered}
\mathrm{P} 1=\left(\mathrm{a}_{11} \mathrm{~A}_{1}+\mathrm{c}_{11} \mathrm{C}_{1}+\mathrm{e}_{11} \mathrm{E}_{1}\right) \\
\mathrm{P} 2=\left(\mathrm{a}_{21} \mathrm{~A}_{1}+\mathrm{a}_{22} \mathrm{~A}_{2}+\mathrm{c}_{21} \mathrm{C}_{1}+\mathrm{c}_{22} \mathrm{C}_{2}+\mathrm{e}_{21} \mathrm{E}_{1}+\mathrm{e}_{22} \mathrm{E}_{2}\right) \\
\mathrm{V}_{\mathrm{P} 1} 1=\mathrm{a}_{11}{ }^{2}+\mathrm{c}_{11}{ }^{2}+\mathrm{e}_{11}{ }^{2} \\
\mathrm{~V}_{\mathrm{P}} 2=\mathrm{a}_{21}{ }^{2}+\mathrm{a}_{21}{ }^{2}+\mathrm{c}_{21}{ }^{2}+\mathrm{c}_{22}{ }^{2}+\mathrm{e}_{21}{ }^{2}+\mathrm{e}_{22}{ }^{2}
\end{gathered}
$$

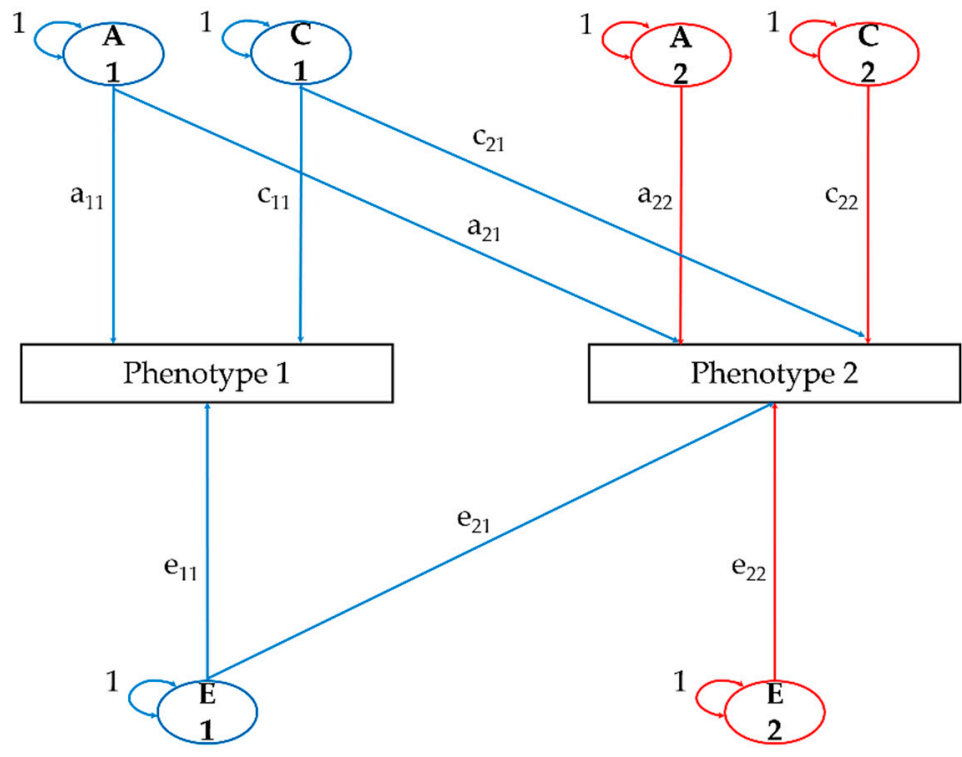

Figure 2. Path diagram for the bivariate Cholesky decomposition model. Subscripts with paths indicate a path direction and an origin (e.g., for $\mathrm{a}_{21}, 2$ is the path direction phenotype 2 , and 1 is the origin). (A) Additive genetic factor; (a) the path from a genetic factor; (C) shared environmental factor; (c) the path from a shared environmental factor; (E) non-shared environmental factor; (e) the path from a non-shared environmental factor.

The variables represent the following: $\mathrm{P} 1=$ phenotype $1 ; \mathrm{V}_{\mathrm{P}} 1=$ total variance of the phenotype 1 ; $\mathrm{P} 2=$ phenotype $2 ; \mathrm{V}_{\mathrm{P}} 2=$ total variance of the phenotype 2 .

Student's t test was used to compare all variables between males and females. Pearson's correlations were used to determine the correlations among all parameters in MZ and DZ twins. Statistical analysis was performed using IBM SPSS Statistics for Windows (version 26.0J, IBM Japan Corp., Tokyo, Japan) and twin SEM was implemented in R (version 3.6.3 for Windows, R Development Core Team, Vienna, Austria) Package OpenMx (version 2.17, OpenMx Development Core Team, VA, USA), adjusted for age and sex [28].

\section{Results}

Table 1 shows the comparison of height, body weight, BMI, SMI, and PhA by sex. No significant difference was observed for age. All parameters in males were higher than those in females $(p<0.001)$. Pearson correlations between anthropometric measurements and $\mathrm{PhA}$ in the $\mathrm{MZ}$ and $\mathrm{DZ}$ groups are presented in Table 2. Of all measurements, only SMI was most strongly correlated with PhA in both 
the MZ group ( $r=0.390)$ and the DZ group $(r=0.605)$. We found that the relationships between SMI and PhA were stronger in the DZ group than the MZ group. No significant correlation was observed between PhA and height or body weight.

Table 1. A comparison of anthropometric measurements and PhA in males and females.

\begin{tabular}{cccccccc}
\hline \multirow{2}{*}{ Variable } & \multicolumn{2}{c}{ Total $(n=\mathbf{1 6 8})$} & \multicolumn{2}{c}{ Male $(n=54)$} & \multicolumn{2}{c}{ Female $(n=114)$} & \\
\cline { 2 - 8 } & Mean & SD & Mean & SD & Mean & SD & $p$-Value \\
\hline Age (years) & 61.0 & 16.5 & 60.7 & 20.9 & 61.1 & 14.0 & 0.903 \\
Height $(\mathrm{cm})$ & 157.8 & 8.23 & 165.9 & 6.30 & 153.9 & 5.95 & $<0.001$ \\
Body Weight $(\mathrm{kg})$ & 53.8 & 10.3 & 63.0 & 9.57 & 49.5 & 7.34 & $<0.001$ \\
BMI $\left(\mathrm{kg} / \mathrm{m}^{2}\right)$ & 21.5 & 3.19 & 22.9 & 3.32 & 20.9 & 2.93 & $<0.001$ \\
SMI $\left(\mathrm{kg} / \mathrm{m}^{2}\right)$ & 6.79 & 1.12 & 7.95 & 0.93 & 6.22 & 0.67 & $<0.001$ \\
PhA $\left({ }^{\circ}\right)$ & 5.46 & 0.88 & 5.94 & 0.92 & 5.24 & 0.76 & $<0.001$ \\
\hline
\end{tabular}

Note: SD: Standard deviation; BMI: Body mass index; SMI: Skeletal muscle mass index; PhA: Phase angle.

Table 2. Pearson correlations between anthropometric measurements and phase angle in monozygotic and dizygotic twins.

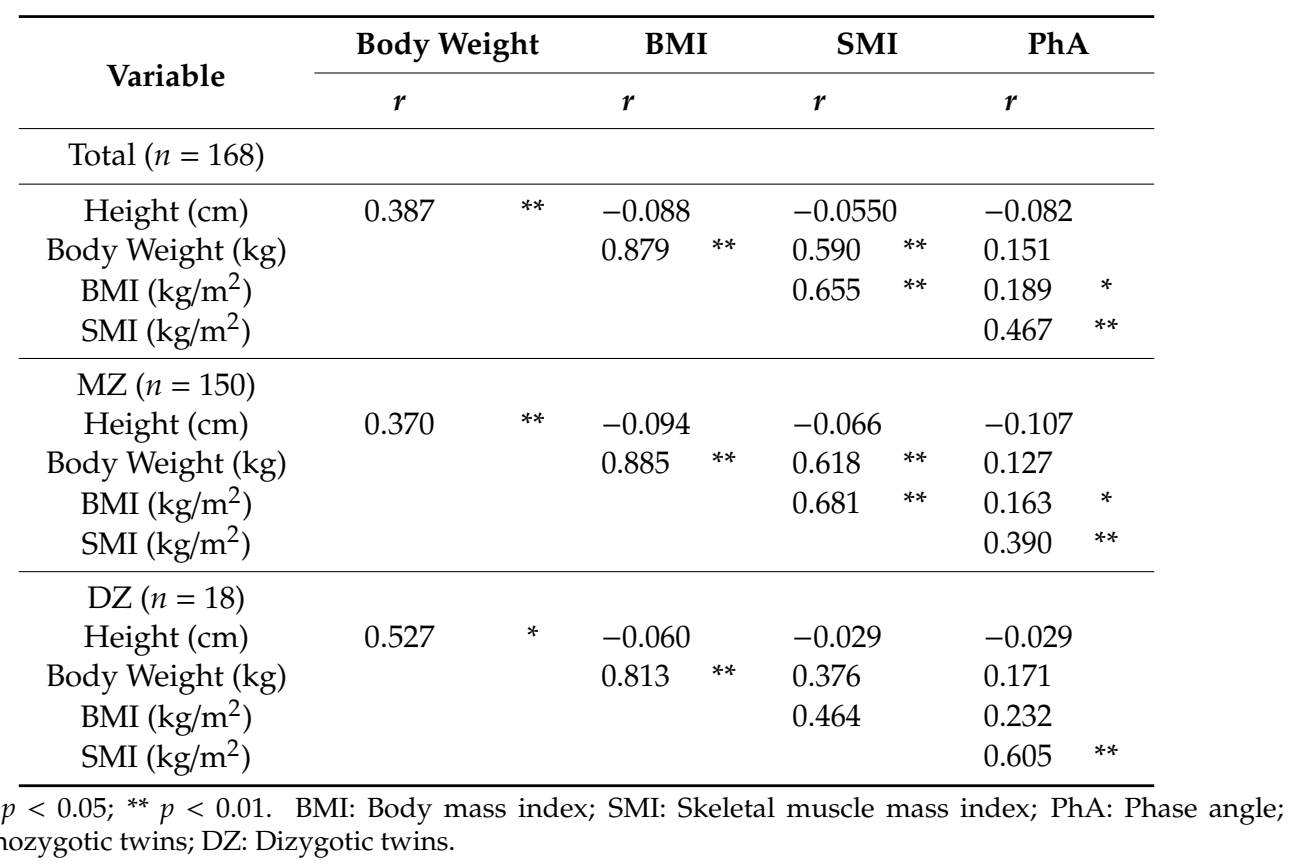

The results of univariate ACE and ADE model fitting and estimated values are shown in Table 3 and Table S1. In the ACE and ADE model (a full model), these models were not fitting, and we cannot estimate values in all phenotypes. In ACE model, the AE model was the best-fitting model because it had lower $-2 \log$ likelihood and Akaike's information criterion than CE model. In addition, the $p$-value suggested that a significant difference was not present between the ACE model and the AE model. Therefore, shared environmental (C) effects had no impact on the total variance of all the phenotypes that were considered. The narrow-sense heritability was estimated using the univariate AE models for all phenotypes. The heritability estimate for height was 0.932 (95\% CI: 0.908-0.950), for body weight was 0.758 (95\% CI: 0.682-0.817), for BMI was 0.718 (95\% CI: 0.630-0.786), and for SMI was 0.513 (95\% CI: 0.457-0.625). For the PhA, 51\% (95\% CI: 0.341-0.642) of the variance was explained by additive genetic effects, and 49\% (95\% CI: 0.358-0.659) was explained by unique environmental (including measurement error) effects (Table 3 ). 
Table 3. Univariate ACE model fitting and estimated values for anthropometric measurements and phase angle.

\begin{tabular}{|c|c|c|c|c|c|c|}
\hline Variable & $-2 L L$ & AIC & $p$-Value & A $(95 \%$ CI $)$ & $\mathrm{C}(95 \% \mathrm{CI})$ & E $(95 \% \mathrm{CI})$ \\
\hline \multicolumn{7}{|c|}{ Height $(\mathrm{cm})$} \\
\hline $\mathrm{ACE}$ & 1782 & 1119 & - & - & - & - \\
\hline $\mathrm{AE}$ & 1783 & 1117 & 0.558 & $0.932(0.908-0.950)$ & - & $0.068(0.050-0.091)$ \\
\hline $\mathrm{CE}$ & 1831 & 1165 & $<0.01$ & - & $0.888(0.851-0.916)$ & $0.112(0.084-0.149)$ \\
\hline $\mathrm{E}$ & 2092 & 1424 & $<0.01$ & - & - & - \\
\hline \multicolumn{7}{|c|}{ Body Weight (kg) } \\
\hline ACE & 2228 & 1564 & - & - & - & - \\
\hline $\mathrm{AE}$ & 2228 & 1562 & 1.000 & $0.758(0.682-0.817)$ & - & $0.242(0.183-0.318)$ \\
\hline $\mathrm{CE}$ & 2241 & 1575 & $<0.01$ & - & $0.704(0.619-0.772)$ & $0.296(0.228-0.381)$ \\
\hline $\mathrm{E}$ & 2356 & 1688 & $<0.01$ & - & - & - \\
\hline \multicolumn{7}{|l|}{$\mathrm{BMI}\left(\mathrm{kg} / \mathrm{m}^{2}\right)$} \\
\hline ACE & 1568 & 904.0 & - & - & - & - \\
\hline $\mathrm{AE}$ & 1568 & 902.0 & 1.000 & $0.718(0.630-0.786)$ & - & $0.282(0.214-0.370)$ \\
\hline $\mathrm{CE}$ & 1585 & 919.1 & $<0.01$ & - & $0.645(0.548-0.725)$ & $0.355(0.275-0.451)$ \\
\hline $\mathrm{E}$ & 1675 & 1007 & $<0.01$ & - & - & - \\
\hline \multicolumn{7}{|c|}{$\mathrm{SMI}\left(\mathrm{kg} / \mathrm{m}^{2}\right)$} \\
\hline $\mathrm{ACE}$ & 699.8 & 55.83 & - & - & - & - \\
\hline $\mathrm{AE}$ & 700.4 & 54.43 & 0.439 & $0.513(0.457-0.625)$ & - & $0.487(0.375-0.543)$ \\
\hline $\mathrm{CE}$ & 700.9 & 54.89 & 0.304 & - & $0.467(0.337-0.579)$ & $0.533(0.421-0.663)$ \\
\hline $\mathrm{E}$ & 740.1 & 92.10 & $<0.01$ & - & - & - \\
\hline \multicolumn{7}{|l|}{$\operatorname{PhA}\left({ }^{\circ}\right)$} \\
\hline $\mathrm{ACE}$ & 1783 & 1119 & - & - & - & - \\
\hline $\mathrm{AE}$ & 1783 & 1117 & 0.558 & $0.506(0.341-0.642)$ & - & $0.494(0.358-0.659)$ \\
\hline $\mathrm{CE}$ & 1831 & 1165 & $<0.01$ & - & $0.281(0.137-0.414)$ & $0.718(0.585-0.863)$ \\
\hline $\mathrm{E}$ & 2092 & 1424 & $<0.01$ & - & - & - \\
\hline
\end{tabular}

Note: BMI: Body mass index; SMI: Skeletal muscle mass index; PhA: Phase angle; $p$-value for statistical difference versus ACE model. -2LL: -2 log-likelihood; AIC: Akaike's information criterion; A: Additive genetic factor; C: Shared environmental factor; E, non-shared environmental factor; CI: Confidence interval.

Next, we applied the AE model to perform Cholesky decomposition. The standardized path coefficients are shown in Figures 3 and 4. In the bivariate analysis between PhA and SMI, we found that the non-shared environmental factor $\mathrm{e}_{21}(15 \%)$ contributed a higher proportion of the total variance of VP2 than additive genetic factor $\mathrm{a}_{21}(8 \%)$ (Figure 3). Figure 4 shows the Cholesky decomposition path diagram among all phenotypes for the AE Model. Although A1 (common additive genetic factor) explained $50 \%$ of VP1 for PhA, it explained less than $10 \%$ of variance for the other phenotypes. For E1 explained by unique environmental factors for PhA, $\mathrm{e}_{21}(14 \%)$, which was common with SMI, contributed the highest proportion of variance.

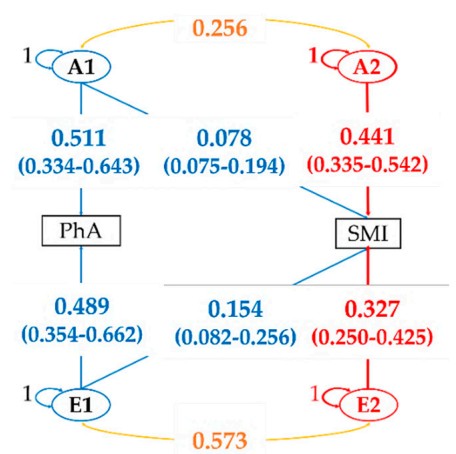

Figure 3. Cholesky decomposition path diagram between phase angle and skeletal muscle mass index for the AE model. Standardized path coefficients are presented. Numbers in parentheses are $95 \%$ confidence intervals of estimates. The number between (A1) and (A2) and the number between (E1) and (E2) are correlation coefficients. (A1-2) Additive genetic factor; (E1-2) Non-shared environmental factor; PhA: Phase angle; SMI: Skeletal muscle mass index. 


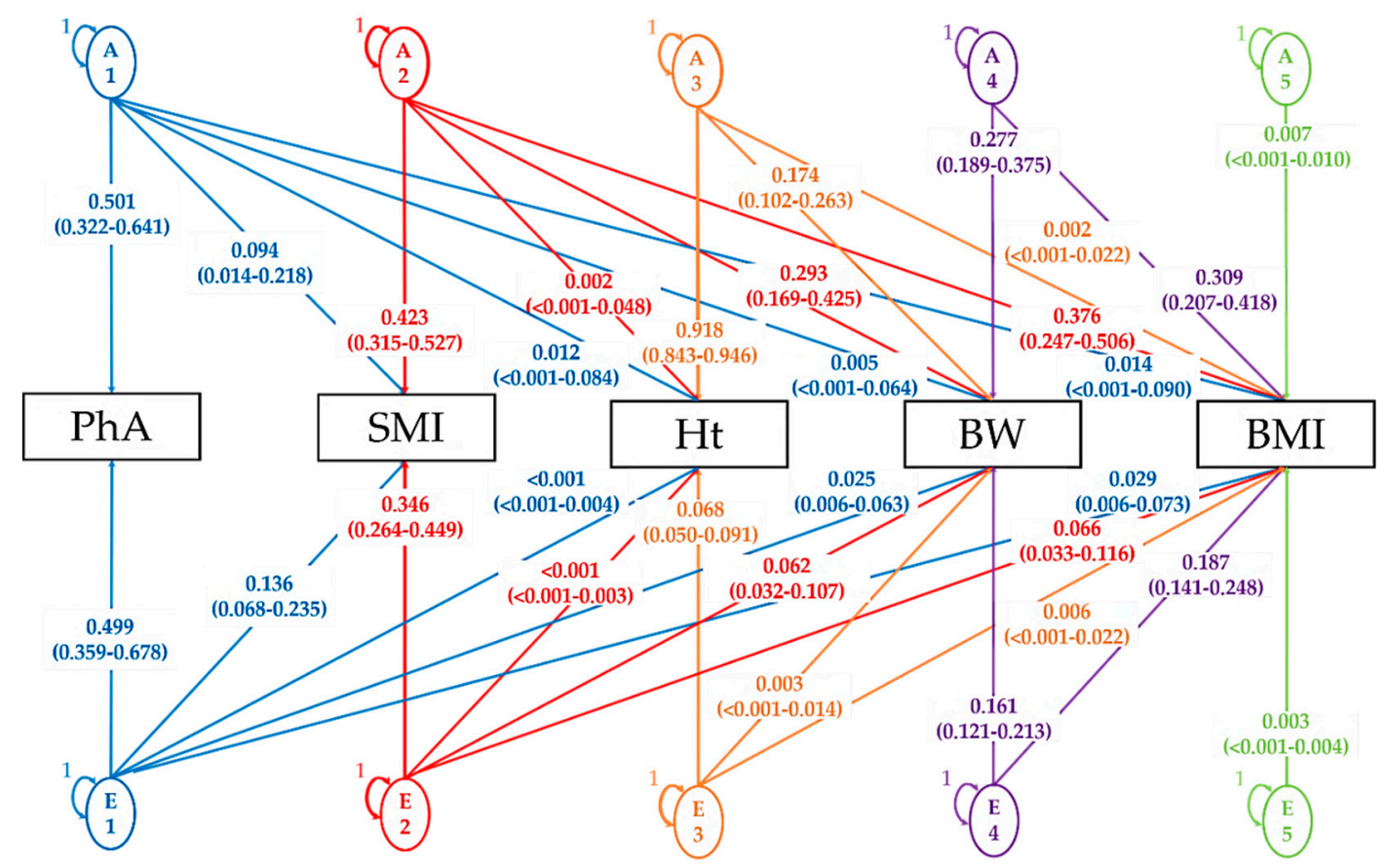

Figure 4. Cholesky decomposition path diagram among anthropometric measurements and phase angle for the AE model. Standardized path coefficients are presented. Numbers in parentheses are $95 \%$ confidence intervals of estimates. (A1-A5) additive genetic factor; (E1-5) non-shared environmental factor; PhA: Phase angle; SMI: Skeletal muscle mass index; Ht: Height; BW: Body weight; BMI: Body mass index.

\section{Discussion}

In our study, we aimed to estimate the heritability of $\mathrm{PhA}$ and to investigate the genetic and environmental aspects of the relationships between anthropometric measurements and $\mathrm{PhA}$. The distribution of PhA and the other measurements in this study was relatively normal for Asians. $\mathrm{PhA}$ usually ranges between $5-7^{\circ}$ in healthy adults and is usually lower in women than men $[29,30]$. Our results confirmed that height (0.932), body weight (0.758) and BMI (0.718) were highly heritable, similar to previous studies that reported that, for example, the heritability of BMI was $0.51-0.81$ for 20-79 years old [20,21].

Our main results for PhA showed that additive genetic effects explained $51 \%$ of the variance, whereas unique environmental effects explained the rest of the variance. The heritability of PhA was lower than that of anthropometric measurements such as BMI. It is the first study to clarify the heritability of BIA-derived PhA. This finding could help more in the accurate interpretation of PhA. These results indicate that $\mathrm{PhA}$ is more strongly affected by environmental effects, that is, it is more modifiable than BMI.

Cholesky decomposition showed that PhA shared little genetic and environmental effects with height, body weight, or BMI. In fact, PhA is an independent parameter. Environmental factors for PhA contribute to more variance in SMI than genetic factors. That is, the phenotypic relationship between PhA and SMI was mediated in part by common environmental influences. The unique environment includes measurement error in the classical twin design [23]. However, this correlation was unexplainable by only measurement error. The cause of the phenotypic relationship between PhA and SMI may be explained by the relationship to sarcopenia [31,32]. For example, resistance training (RT) has a common environmental effect on both PhA and SMI. Although the physiological mechanisms by which RT improves PhA are not fully understood, the PhA change due to RT may be attributed to some known factors [33-35]. PhA can be affected by changes in the capacitive behavior of the tissues, cell size and mass, cell membrane permeability, or intracellular composition [36]. RT-induced 
changes seem to counteract age-related decreases in PhA [33]. However, genetic factors may explain the individual variation in the response to this intervention [37]. An intervention needs to be adjusted to the patient's response as indicated by parameters such as PhA and SMI [38].

This study has some limitations. First, these findings were derived from a cross-sectional design. Second, the sample size of the study was small, particularly for the DZ group. Third, PhA may be affected by physical activity [39] and nutritional status [3-5]. Finally, because our participants were Japanese, application to other races, ethnicities, and residents of other countries is difficult. Future studies with a longitudinal design, larger number of participants, more potential confounding factors, and international collaborations are needed to confirm our results.

\section{Conclusions}

In conclusion, this study provided new insights into the genetic and environmental effects on $\mathrm{PhA}$. Our findings suggest that PhA could be a practical and independent parameter of genetic determinants of physical health. The correlation between PhA and SMI was explained more strongly by environmental factors than genetic factors.

Supplementary Materials: The following are available online at http://www.mdpi.com/1660-4601/17/21/7810/s1, Table S1: Univariate ADE model fitting and standardized path coefficients for anthropometric measurements and phase angle.

Author Contributions: Conceptualization, D.M. and F.I.; methodology, D.M. and F.I.; software, D.M. and F.I.; validation, D.M. and F.I.; formal analysis, D.M. and F.I.; investigation, D.M., F.I., C.H., and R.T.; resources, D.M. and F.I.; data curation, C.H. and R.T.; writing-Original draft preparation, D.M. and F.I.; writing-Review and editing, D.M., F.I., C.H., R.T., M.W., N.S.; and K.S. visualization, D.M.; supervision, N.S.; project administration, N.S.; funding acquisition, D.M., F.I., C.H., R.T., M.W., and N.S. All authors have read and agreed to the published version of the manuscript.

Funding: This work was supported by JSPS KAKENHI Grant Numbers JP16K21530, JP16K15978, JP17H04134, JP19K10673, JP19H04048, JP19KK0244, JP20K11091, and University Grants from Japanese Ministry of Education, Culture, Sports, Science and Technology.

Acknowledgments: The authors are thankful to all the consultants from the Osaka Twin Research Group (Norio Sakai, Masanori Takahashi, Hisashi Tanaka, Kei Kamide, Shinji Kihara, Hiroko Watanabe, Mikio Watanabe, Hiroto Takahashi, and Rie Tomizawa) and all the technical and secretarial staff of the Center for Twin Research, Osaka University Graduate School of Medicine.

Conflicts of Interest: The authors declare no conflict of interest.

\section{References}

1. De Lorenzo, A.; Andreoli, A.; Matthie, J.; Withers, P. Predicting body cell mass with bioimpedance by using theoretical methods: A technological review. J. Appl. Physiol. 1997, 82, 1542-1558. [CrossRef] [PubMed]

2. Kyle, U.G.; Bosaeus, I.; De Lorenzo, A.D.; Deurenberg, P.; Elia, M.; Manuel Gomez, J.; Lilienthal Heitmann, B.; Kent-Smith, L.; Melchior, J.C.; Pirlich, M.; et al. Bioelectrical impedance analysis-Part II: Utilization in clinical practice. Clin. Nutr. 2004, 23, 1430-1453. [CrossRef] [PubMed]

3. Kyle, U.G.; Genton, L.; Pichard, C. Low phase angle determined by bioelectrical impedance analysis is associated with malnutrition and nutritional risk at hospital admission. Clin. Nutr. 2013, 32, $294-299$. [CrossRef]

4. Kyle, U.G.; Soundar, E.P.; Genton, L.; Pichard, C. Can phase angle determined by bioelectrical impedance analysis assess nutritional risk? A comparison between healthy and hospitalized subjects. Clin. Nutr. 2012, 31, 875-881. [CrossRef] [PubMed]

5. Lee, Y.; Kwon, O.; Shin, C.S.; Lee, S.M. Use of bioelectrical impedance analysis for the assessment of nutritional status in critically ill patients. Clin. Nutr. Res. 2015, 4, 32-40. [CrossRef]

6. Garlini, L.M.; Alves, F.D.; Ceretta, L.B.; Perry, I.S.; Souza, G.C.; Clausell, N.O. Phase angle and mortality: A systematic review. Eur. J. Clin. Nutr. 2019, 73, 495-508. [CrossRef]

7. Yamada, M.; Kimura, Y.; Ishiyama, D.; Nishio, N.; Otobe, Y.; Tanaka, T.; Ohji, S.; Koyama, S.; Sato, A.; Suzuki, M.; et al. Phase angle is a useful indicator for muscle function in older adults. J. Nutr. Health Aging 2019, 23, 251-255. [CrossRef] 
8. Uemura, K.; Yamada, M.; Okamoto, H. Association of bioimpedance phase angle and prospective falls in older adults. Geriatr. Gerontol. Int. 2019, 19, 503-507. [CrossRef]

9. Wilhelm-Leen, E.R.; Hall, Y.N.; Horwitz, R.I.; Chertow, G.M. Phase angle, frailty and mortality in older adults. J. Gen. Intern. Med. 2014, 29, 147-154. [CrossRef]

10. Uemura, K.; Doi, T.; Tsutsumimoto, K.; Nakakubo, S.; Kim, M.J.; Kurita, S.; Ishii, H.; Shimada, H. Predictivity of bioimpedance phase angle for incident disability in older adults. J. Cachexia Sarcopenia Muscle 2020, 11, 46-54. [CrossRef]

11. Norman, K.; Wirth, R.; Neubauer, M.; Eckardt, R.; Stobaus, N. The bioimpedance phase angle predicts low muscle strength, impaired quality of life, and increased mortality in old patients with cancer. J. Am. Med. Dir. Assoc. 2015, 16, 173.e17-173.e22. [CrossRef] [PubMed]

12. Yamada, Y.; Buehring, B.; Krueger, D.; Anderson, R.M.; Schoeller, D.A.; Binkley, N. Electrical properties assessed by bioelectrical impedance spectroscopy as biomarkers of age-related loss of skeletal muscle quantity and quality. J. Gerontol. A Biol. Sci. Med. Sci. 2017, 72, 1180-1186. [CrossRef] [PubMed]

13. Basile, C.; Della-Morte, D.; Cacciatore, F.; Gargiulo, G.; Galizia, G.; Roselli, M.; Curcio, F.; Bonaduce, D.; Abete, P. Phase angle as bioelectrical marker to identify elderly patients at risk of sarcopenia. Exp. Gerontol. 2014, 58, 43-46. [CrossRef] [PubMed]

14. Cunha, P.M.; Tomeleri, C.M.; Nascimento, M.A.D.; Nunes, J.P.; Antunes, M.; Nabuco, H.C.G.; Quadros, Y.; Cavalcante, E.F.; Mayhew, J.L.; Sardinha, L.B.; et al. Improvement of cellular health indicators and muscle quality in older women with different resistance training volumes. J. Sports Sci. 2018, 36, 2843-2848. [CrossRef] [PubMed]

15. Heymsfield, S.B.; Gonzalez, M.C.; Lu, J.H.; Jia, G.; Zheng, J.N. Skeletal muscle mass and quality: Evolution of modern measurement concepts in the context of sarcopenia. Proc. Nutr. Soc. 2015, 74, 355-366. [CrossRef] [PubMed]

16. Cruz-Jentoft, A.J.; Bahat, G.; Bauer, J.; Boirie, Y.; Bruyere, O.; Cederholm, T.; Cooper, C.; Landi, F.; Rolland, Y.; Sayer, A.A.; et al. Sarcopenia: Revised European consensus on definition and diagnosis. Age Ageing 2019, 48, 16-31. [CrossRef]

17. Polderman, T.J.; Benyamin, B.; de Leeuw, C.A.; Sullivan, P.F.; van Bochoven, A.; Visscher, P.M.; Posthuma, D. Meta-analysis of the heritability of human traits based on fifty years of twin studies. Nat. Genet. 2015, 47, 702-709. [CrossRef]

18. Silventoinen, K.; Jelenkovic, A.; Sund, R.; Honda, C.; Aaltonen, S.; Yokoyama, Y.; Tarnoki, A.D.; Tarnoki, D.L.; Ning, F.; Ji, F.; et al. The CODATwins project: The cohort description of collaborative project of development of anthropometrical measures in twins to study macro-environmental variation in genetic and environmental effects on anthropometric traits. Twin Res. Hum. Genet. 2015, 18, 348-360. [CrossRef]

19. Silventoinen, K.; Jelenkovic, A.; Sund, R.; Yokoyama, Y.; Hur, Y.M.; Cozen, W.; Hwang, A.E.; Mack, T.M.; Honda, C.; Inui, F.; et al. Differences in genetic and environmental variation in adult BMI by sex, age, time period, and region: An individual-based pooled analysis of 40 twin cohorts. Am. J. Clin. Nutr. 2017, 106, 457-466. [CrossRef]

20. Elder, S.J.; Roberts, S.B.; McCrory, M.A.; Das, S.K.; Fuss, P.J.; Pittas, A.G.; Greenberg, A.S.; Heymsfield, S.B.; Dawson-Hughes, B.; Bouchard, T.J., Jr.; et al. Effect of body composition methodology on heritability estimation of body fatness. Open Nutr. J. 2012, 6, 48-58. [CrossRef]

21. Tarnoki, A.D.; Tarnoki, D.L.; Medda, E.; Cotichini, R.; Stazi, M.A.; Fagnani, C.; Nistic, A.L.; Lucatelli, P.; Boatta, E.; Zini, C.; et al. Bioimpedance analysis of body composition in an international twin cohort. Obes. Res. Clin. Pract. 2014, 8, e201-e298. [CrossRef] [PubMed]

22. Yamada, Y.; Nishizawa, M.; Uchiyama, T.; Kasahara, Y.; Shindo, M.; Miyachi, M.; Tanaka, S. Developing and validating an age-independent equation using multi-frequency bioelectrical impedance analysis for estimation of appendicular skeletal muscle mass and establishing a cutoff for Sarcopenia. Int. J. Environ. Res. Public Health 2017, 14, 809. [CrossRef] [PubMed]

23. Van Dongen, J.; Slagboom, P.E.; Draisma, H.H.; Martin, N.G.; Boomsma, D.I. The continuing value of twin studies in the omics era. Nat. Rev. Genet. 2012, 13, 640-653. [CrossRef]

24. Rijsdijk, F.V.; Sham, P.C. Analytic approaches to twin data using structural equation models. Brief. Bioinform. 2002, 3, 119-133. [CrossRef] [PubMed]

25. Grayson, D.A. Twins reared together: Minimizing shared environmental effects. Behav. Genet. 1989, 19, 593-604. [CrossRef] [PubMed] 
26. Akaike, H. Factor analysis and AIC. Psychometrika 1987, 52, 317-332. [CrossRef]

27. Loehlin, J.C. The Cholesky approach: A cautionary note. Behav. Genet. 1996, 26, 65-69. [CrossRef]

28. Neale, M.C.; Hunter, M.D.; Pritikin, J.N.; Zahery, M.; Brick, T.R.; Kirkpatrick, R.M.; Estabrook, R.; Bates, T.C.; Maes, H.H.; Boker, S.M. OpenMx 2.0: Extended structural equation and statistical modeling. Psychometrika 2016, 81, 535-549. [CrossRef]

29. Barbosa-Silva, M.C.; Barros, A.J.; Wang, J.; Heymsfield, S.B.; Pierson, R.N., Jr. Bioelectrical impedance analysis population reference values for phase angle by age and sex. Am. J. Clin. Nutr. 2005, 82, 49-52. [CrossRef]

30. Bosy-Westphal, A.; Danielzik, S.; Dorhofer, R.P.; Later, W.; Wiese, S.; Muller, M.J. Phase angle from bioelectrical impedance analysis: Population reference values by age, sex, and body mass index. J. Parenter. Enteral. Nutr. 2006, 30, 309-316. [CrossRef]

31. Santana, N.M.; Pinho, C.P.S.; da Silva, C.P.; dos Santos, N.F.; Mendes, R.M.L. Phase angle as a sarcopenia marker in hospitalized elderly patients. Nutr. Clin. Pract. 2018, 33, 232-237. [CrossRef] [PubMed]

32. Kilic, M.K.; Kizilarslanoglu, M.C.; Arik, G.; Bolayir, B.; Kara, O.; Dogan Varan, H.; Sumer, F.; Kuyumcu, M.E.; Halil, M.; Ulger, Z. Association of bioelectrical impedance analysis-derived phase angle and sarcopenia in older adults. Nutr. Clin. Pract. 2017, 32, 103-109. [CrossRef] [PubMed]

33. Souza, M.F.; Tomeleri, C.M.; Ribeiro, A.S.; Schoenfeld, B.J.; Silva, A.M.; Sardinha, L.B.; Cyrino, E.S. Effect of resistance training on phase angle in older women: A randomized controlled trial. Scand. J. Med. Sci. Sports 2017, 27, 1308-1316. [CrossRef] [PubMed]

34. Ribeiro, A.S.; Schoenfeld, B.J.; Souza, M.F.; Tomeleri, C.M.; Silva, A.M.; Teixeira, D.C.; Sardinha, L.B.; Cyrino, E.S. Resistance training prescription with different load-management methods improves phase angle in older women. Eur. J. Sport Sci. 2017, 17, 913-921. [CrossRef]

35. Sardinha, L.B. Physiology of exercise and phase angle: Another look at BIA. Eur. J. Clin. Nutr. 2018, 72, 1323-1327. [CrossRef]

36. Norman, K.; Stobaus, N.; Pirlich, M.; Bosy-Westphal, A. Bioelectrical phase angle and impedance vector analysis-Clinical relevance and applicability of impedance parameters. Clin. Nutr. 2012, 31, 854-861. [CrossRef]

37. Zadro, J.R.; Shirley, D.; Andrade, T.B.; Scurrah, K.J.; Bauman, A.; Ferreira, P.H. The beneficial effects of physical activity: Is it down to your genes? A systematic review and meta-analysis of twin and family studies. Sports Med. Open 2017, 3, 1-19. [CrossRef]

38. Churchward-Venne, T.A.; Tieland, M.; Verdijk, L.B.; Leenders, M.; Dirks, M.L.; de Groot, L.C.; van Loon, L.J. There are no nonresponders to resistance-type exercise training in older men and women. J. Am. Med. Dir. Assoc. 2015, 16, 400-411. [CrossRef]

39. Dittmar, M. Reliability and variability of bioimpedance measures in normal adults: Effects of age, gender, and body mass. Am. J. Phys. Anthropol. 2003, 122, 361-370. [CrossRef]

Publisher's Note: MDPI stays neutral with regard to jurisdictional claims in published maps and institutional affiliations.

(C) 2020 by the authors. Licensee MDPI, Basel, Switzerland. This article is an open access article distributed under the terms and conditions of the Creative Commons Attribution (CC BY) license (http://creativecommons.org/licenses/by/4.0/). 